\title{
Alteration in Characteristics and Outcome of Pediatric Burkitt Lymphoma in Turkey: Single-center Experience
}

\author{
Eda BALKAYA, ${ }^{\circ}$ Ceyhun BOZKURT, ${ }^{2}$ () Nazmiye YÜKSEK, ${ }^{3}$ Sonay INCESOY ÖZDEMIR, ${ }^{4}$ \\ Gürses ŞAHIN ${ }^{5}$
}

\begin{abstract}
'Department of Pediatric Hematology and Oncology, Ankara Gülhane Training and Research Hospital, Ankara-Turkey ${ }^{2}$ Department of Pediatric Hematology and Oncology, Medical Park International Hospital, İstanbul-Turkey ${ }^{3}$ Department of Pediatric Hematology and Oncology, Bülent Ecevit University Faculty of Medicine, Zonguldak-Turkey ${ }^{4}$ Department of Pediatric Hematology and Oncology, Yıldırım Beyazıt University Yenimahalle Training and Research Hospital, Ankara-Turkey ${ }^{5}$ Department of Pediatric Hematology and Oncology, Dr. Sami Ulus Maternity, Children's Health and Diseases Training and Research Hospital, Ankara-Turkey
\end{abstract}

\section{OBJECTIVE}

Burkitt Lymphoma (BL) is an aggressive and rapidly progressive form of non-Hodgkin's lymphomas (NHL), and BL gives rise to 3-4\% of all childhood malignancies. Its event-free survival has increased up to $85 \%$ with current treatment protocols. In this study, we aimed to investigate whether there are some alterations of the clinical and laboratory features of BL at our center in Turkey before and now, or not.

\section{METHODS}

We gathered medical records of a total of 101 patients with BL who were treated in our center retrospectively and assessed for laboratory findings, clinical characteristics, prognostic factors and treatment protocols.

\section{RESULTS}

We found that, nowadays, intra-abdominal presentation of BL was seen more frequently than past at our center in Turkey. However, there was no statistically significant difference. BL was numerically meaningful. Murphy's treatment protocol was more satisfactory compared to past treatment protocols.

\section{CONCLUSION}

Our comparison of the previous and present features of patients showed that there is a shift away from the jaw to mostly intra-abdominal disease presentation at our center, like Uganda, in the course of time. And we also have a large number of patients and the follow-up period is very long (median 111 months for all patients) in the literature. We think that the intra-abdominal component is seen more in our geography with time, but it should be evaluated with more studies in other geographies, especially in Europe and America.

Keywords: Burkitt lymphoma; childhood; epidemiology; treatment.

Copyright $\odot$ 2020, Turkish Society for Radiation Oncology

\section{Introduction}

Burkitt Lymphoma (BL) is an aggressive and rapidly progressive form of non-Hodgkin's lymphomas
(NHL). BL brings about 3-4\% of all childhood malignancies diagnosed each year in the United States (US). $[1,2]$ Significant improvements have occurred in the outcome, and event-free survival has increased up to

\section{Dr. Eda BALKAYA}

Ankara Gülhane Eğitim ve Araştırma Hastanesi,

Çocuk Hematoloji ve Onkoloji Kliniği,

Ankara-Turkey

E-mail: edabalkaya@yahoo.com 
$85 \%$ with current treatment protocols.[1] At present, $\mathrm{BL}$ is classified as two main variants as follows: endemic (African) and sporadic (non-endemic) forms. [3] Between the two forms, there are differences in the clinical presentation, epidemiology, and genetic features. The endemic form often involves the jaw and is observed in Equatorial Africa, whereas sporadic form frequently exists in abdominal organs and observed worldwide (especially US and Western Europe). In addition, the sporadic form is more prevalent in males and at an older age (mean 10 age) than the endemic form (mean 7 age). Bone marrow (BM) involvement is more frequently observed in a sporadic form, whereas central system involvement (CNS) is more frequently observed in the endemic form. [2,4-8]

Previous studies from Turkey showed that Turkish BL appears in a form that is between the endemic and the sporadic form. A recent study showed that there are some changes in the endemic form in Uganda over time.[9] Also, we designed this study on whether there are some differences in the clinical and laboratory features of BL at our center in Turkey before and now or not and also with treatment protocols.

\section{Materials and Methods}

This study included 101 patients under the age of 18 years who were diagnosed, followed up and treated in our clinic between January 1991 and December 2011. Medical history and physical examination were obtained from records. Patients with BL (L3 type blasts were more than $25 \%$ in the bone marrow aspiration) and patients who left the treatment were excluded from this study. Then, we evaluated 101 patients in total. We divided them into two groups due to the number of patients and treatment protocols. Between 1991 and 1998,52 patients were treated with the GRAB treatment protocol, but the treatment protocol switched to Murphy regimen ( $n=49)$ between 1999 and 2011, increasing intensity over the years. The GRAB and the Murphy regimens were described in Al-Attar et al.s study [10] and in Murphy et al's study [11], respectively. Complete blood count, serum chemistry, serum lactate dehydrogenase (LDH), bone marrow (BM) aspiration, cerebrospinal fluid (CSF) examination, chest $\mathrm{x}$-ray, ultrasonography, computed tomography (CT) or magnetic resonance imaging (MRI) results of patients were investigated. Cases were diagnosed by cytology or histology. The St Jude staging system was used.[11] Leucocytosis and anemia were defined by age.[5] We diagnosed central nervous system (CNS) involvement as lymphoma cells in the cerebrospinal fluid (CSF), cerebral infiltrates on cranial CT or MRI, or cranial nerve palsy that was not caused by an extradural mass.

We considered complete remission (CR) as the disappearance of all tumor masses confirmed by clinical examination and imaging investigations. Progressive disease (PD) was defined as the tumor site and other pathological findings showed no decrease after the initiation of treatment. The reappearance of lymphoma with the same histological or immunophenotypic features after achieving CR or PR was considered as Relapse. Event-free survival (EFS) was defined as the time from the initial treatment to the time of progression, relapse, death or the recent follow-up examination. The overall survival (OS) was considered from the initiation of treatment to death or the last follow-up examination.[12]

\section{Statistical Methods}

$\chi^{2}$ test or Fisher's Exact Test were used to examine the differences in the distribution of individual parameters among patients. The prognostic factors were assessed using the Kaplan-Meier method. Statistical significance between treatment protocols was assessed using the Anova test. Mann-Whitney U and T-tests were used to compare nonparametric continuous variables. Survival analyses were compared using the log-rank test and survival curves were generated with the Kaplan-Meier method. Multivariate analysis using Cox proportional hazard regression method was completed to determine the independent prognostic factors influencing EFS. All calculations were obtained using SPSS version 15.0 statistical software.

\section{Results}

In our study, the treatment protocols were GRAB in 52 patients between 1991-1999 and Murphy in 49 patients between 2000-2011. The clinicopathologic properties of the two groups are represented in Table 1.

The mean age was 6.5 years (range of 2.6-14 years) and 6.2 years (range of 2.7-14.3 years) in the GRAB group and Murphy group, respectively. The male-to-female ratio was 3.7:1 and 1.8:1 in the the GRAB group and Murphy group, respectively. The most common primary tumor site was abdomen in two groups ( 42 patients, $80.7 \%$ in the GRAB group and 43 patients, $87.8 \%$ in the Murphy group). While 10 of the 52 patients had combined jaw and abdomen presentation in the GRAB group, three of 49 patients had combined jaw and abdomen presentation in the Murphy group. 
Table 1 The clinicopathologic features of the two groups

\begin{tabular}{|c|c|c|}
\hline Findings & GRAB & Murphy \\
\hline Number of patients & 52 & 49 \\
\hline Years & 1991-1999 & $2000-2011$ \\
\hline Age of diagnosis & 6.5 years $(2.6-14)$ & 6.2 years $(2.7-14.3)$ \\
\hline \multirow[t]{3}{*}{ Sex } & 41 (78.8\%) male, & $32(65.3 \%)$ male, \\
\hline & $11(21.2 \%)$ female & 17 (34.7\%) female \\
\hline & $3.7: 1$ & $1.8: 1$ \\
\hline \multicolumn{3}{|l|}{ Primary tumor site } \\
\hline Abdominal organs except jaw & $42(80.7 \%)$ & $43(87.8 \%)$ \\
\hline Combined jaw and abdomen & $10(19.2 \%)$ & $3(6.1 \%)$ \\
\hline Only testis & 0 & $1(2.0 \%)$ \\
\hline Only cervical lymph node & 0 & $1(2.0 \%)$ \\
\hline Only jaw & 0 & $1(2.0 \%)$ \\
\hline \multicolumn{3}{|l|}{ Laboratory } \\
\hline Anemia by age & $28(53.8 \%)$ & $31(63.2 \%)$ \\
\hline Leukocytosis by age & $10(19.2 \%)$ & $9(18.3 \%)$ \\
\hline \multicolumn{3}{|l|}{ Stage } \\
\hline Early-stage (I-II) & $6(11.5 \%)$ & $4(8.2 \%)$ \\
\hline Advanced stage (III-IV) & $46(88.5 \%)$ & $45(91.8 \%)$ \\
\hline BM involvement & $0(0 \%)$ & $3(6.1 \%)$ \\
\hline CNS involvement & $4(7.7 \%)$ & $4(8.2 \%)$ \\
\hline Findings & GRAB & Murphy \\
\hline \multicolumn{3}{|l|}{ Complications } \\
\hline Tumor lysis syndrome & $19(36.5 \%)$ & 23 (46.9\%) \\
\hline Hemodialysis & $3(5.7 \%)$ & $2(4.1 \%)$ \\
\hline Peritoneal dialysis & $4(7.7 \%)$ & $3(6.1 \%)$ \\
\hline
\end{tabular}

GRAB: the GRAB treatment protocol which was described in Al-Attar et al's study [10]; BM: Bone marrow; CNS: Central system

Just one patient had only jaw involvement and he is in the Murphy group. Considering 14 patients with jaw presentation in all patients, no BM involvement was present in them and five of them (35.7\%) had a detectable CNS involvement. In addition, four of five patients who had CNS involvement were in the GRAB group, so they had been diagnosed in former times.

While there was no bone marrow (BM) involvement and four patients $(7.7 \%)$ had CNS involvement in the GRAB therapy group, there were three patients $(6.1 \%)$ who had BM involvement and four patients $(8.2 \%)$ had CNS involvement in the Murphy therapy group. According to the St. Jude staging system, 46 patients $(88.4 \%)$ and 45 patients (91.8\%) were in advanced stages (III-IV), in GRAB and Murphy group, respectively.

In the GRAB group, 17 patients died due to progressive disease $(n=12)$, tumor lysis $(n=2)$, sepsis $(\mathrm{n}=2)$, and Steven Johnson Syndrome $(\mathrm{n}=1)$. Also, in Murphy group, eight patients died due to progressive disease $(n=6)$, sepsis $(n=1)$, and measles pneumonia $(\mathrm{n}=1)$. While the follow-up period was 0.5-249 months (median 156 months) for the GRAB group, the follow- up period was 4-152 months (median 85 months) for the Murphy group.

While there were 18 relapses and 28 remissions in the GRAB therapy group, there were three relapses and 40 remissions in the Murphy therapy group. The situation and survival rates of the patients are shown in Table 2 and Table 3, respectively.

Between the two groups, there was no statistically significant difference in age, gender, serum $\mathrm{WBC}$ and serum hemoglobin levels, stages, CNS and BM involvements. CNS and BM involvements did not have an effect on prognosis. The decrease in jaw presentation or the increase of intra-abdominal presentation was not statistically significant ( $\mathrm{p}>0.5$ ), but it was numerically meaningful. Studies with a larger number of patients are needed.

Only chemotherapy protocol was found to be a significant factor for prognosis. When chemotherapy protocol groups were compared with EFS and OS values, we found statistically significant differences $(p=0.01$, $\mathrm{p}=0.04$ ). In univariate and multivariate analysis, GRAB protocol was found to be an important reverse predic- 
Table 2 Situation of the patients

\begin{tabular}{lcc} 
Findings & GRAB & Murphy \\
\hline Situation & & $40(81.6 \%)$ \\
CR (after first treatment) & $28(53.8 \%)$ & $4(8.2 \%)$ \\
PD & $3(5.7 \%)$ & $3(6.1 \%)$ \\
Relapse & $18(34.6 \%)$ & 1 \\
Second remission post- relapse & 7 & 2 \\
PD post-relapse & 11 & $8(16.4 \%)$ \\
Ex & $17(32.7 \%)$ & 41 (83.6\%) \\
Currently remission & $35(67.3 \%)$ & $4-152$ months (median 85 months)
\end{tabular}

GRAB: the GRAB treatment protocol which was described in Al-Attar et al's study [10]; CR: Complete remission; PD: Progressive disease; Ex: Exitus

Table 3 Survival rates of the patients

\begin{tabular}{lcccc} 
Findings & GRAB & Murphy & p & All patients \\
\hline 5-year EFS & $67.4 \pm 7.1 \%$ & $88.0 \pm 4.6 \%$ & 0.01 & $79.3 \pm 4.1 \%$ \\
5-year OS & $68.5 \pm 6.3 \%$ & $84.9 \pm 4.9 \%$ & 0.04 & $76.6 \pm 4.0 \%$ \\
\hline
\end{tabular}

GRAB: the GRAB treatment protocol which was described in Al-Attar et al.'s study [10]; EFS: Event-free survival; OS: Overall survival

tor factor for OS and EFS ( $\mathrm{p}=0.002)$. Also, at the multivariate analysis, the patients were applied GRAB protocol had seven times more death risk than the group who received Murphy's protocol.

We followed up the patients for mean $104.50 \pm 78.65$ months (1-249 months) and $74.38 \%$ of them were in remission. While the follow-up period was 0.5-249 months (median 156 months) for GRAB group, the follow-up period was 4-152 months (median 85 months) for the Murphy group.

\section{Discussion}

BL constitutes approximately $40 \%$ of all childhood nonHodgkin lymphomas in the United States (US) [8] and our finding (38.6\%) is compatible with this. Examining previous studies from the same center and our country [13-20], the findings showed that the frequency of BL has decreased over time in Turkey.

Previous studies from Turkey showed that Turkish BL appears in a form that is between the endemic and the sporadic form. The study conducted by Ogwang et al. has reported that there are some changes in the endemic form in Uganda over time [9], like our findings. We had to compare our findings only with Ogwang et al.s study since, to our knowledge, there are no other studies in the literature but Ogwang et al.s study.
$\mathrm{BL}$ is often seen in boys. According to the literature, the sporadic form is more prevalent in male and older age than the endemic form. We observed that, nowadays, there was a decrease about age and male sex while comparing with the previous studies from our country [13-20] and GRAB group. We thought that there is a reverse alteration about sex and age by the course of time in Turkey, according to Ogwang et al.[9]

The primary intra-abdominal presentation is approximately $80 \%$ in the sporadic form $[8,21,22]$, while primary jaw presentation is approximately $50 \%$ in the endemic form.[23-25] In our study, the most common primary tumor site was the abdomen in two groups ( 42 patients, $80.7 \%$ in the GRAB group and 43 patients, 87.8 $\%$ in the Murphy group). While 10 of the 52 patients had combined jaw and abdomen presentation in the GRAB group, three of 49 patients had combined jaw and abdomen presentation in the Murphy group. Only one patient had only jaw involvement and he is in the Murphy group. These findings showed that there was a decrease in jaw presentation by the course of time at our center in Turkey, supports Ogwang et al.s study.[9] In the literature, while patients with an endemic form of BL has approximately $8-10 \% \mathrm{BM}$ involvement and $20-33.3 \% \mathrm{CNS}$ involvement [9,23-25], patients with the sporadic form of BL has 14-26\% BM involvement and 8-12\% CNS involvement at diagnosis. $[8,21,22]$

As there was an increase in the rate of BM involvement in time, progression to the sporadic form was observed in our study. In the literature, it was reported that the involvement of the jaw with CNS involvement was more frequently in endemic form. In our study, the jaw presentation with CNS involvement was higher in the GRAB group, but it was decreasing in the course of time.

The majority of the patients in Murphy group $(91.8 \%)$ were detected in the advanced stage like the 
sporadic form (70-78.7\%) [2,26,27] and it is a bit more than the GRAB group (88.4\%) and the previous studies from Turkey (74.9-92.1\%).[13-20] This observation is parallel with Ogwnag et al.s study.[9] When 5-year EFS and OS of the patients were compared to an early and advanced stage, there were no significant differences statistically, like Karadeniz et al's research.[19]

Initial $\mathrm{LDH}$ and $\mathrm{Hgb}$ levels ( $\mathrm{LDH}>500 \mathrm{U} / \mathrm{L}$ and $\mathrm{Hgb}<10 \mathrm{mg} / \mathrm{dL}$ ) in $\mathrm{BL}$ are considered as poor prognostic criteria, even affecting staging. However, in our patients, no correlation was determined between $\mathrm{Hgb}, \mathrm{LDH}$, WBC levels and the prognosis of patients. The LDH level is very important. However, we did not compare $\mathrm{LDH}$ levels because there were missing results about our past data. We think that this arises from the incomplete data of some of the patients. Patients with BL are reported to be generally ex due to tumor lysis, renal failure, sepsis and disease progression. Murphy treatment group's results were more favorable than GRAB. Thus, progression and relapse rates were seen less frequently. The results of our study were better than the results of Murphy's own study. The tumor lysis-related mortality rates were less frequently observed, which may be due to the better conditions of care than the previous conditions.

In the course of time, EFS and OS have increased by the use of short-term and intensive chemotherapy protocols. [8,27,28] Our patients' results (5-year EFS $79.3 \pm 4.1 \%$ and OS $76.6 \pm 4.0 \%$ ) were in proximity to the recent studies from the globe. When our patients' OS and EFS were compared to Al-Attar's study (GRAB regimen) $[10,29]$ and Murphy's study $[11,30]$, the treatment results of our study were higher than these values, which may be due to the time interval or better hospital conditions and supportive therapies.

\section{Limitations}

We had to compare our findings only with Ogwang et al.s study since, to our knowledge, there are no other studies in the literature apart from Ogwang et al.s study. Also, the LDH level is very important. However, we did not compare LDH levels, because there were missing results about our past data.

\section{Conclusion}

The most important factor affecting survival in our study was the treatment protocol. Also, supportive therapies for complications during chemotherapy seen as the second important factors in improving prognosis. In the literature, this is one of the longest follow-up and the largest series of children with very good results in BL.
Previous studies from Turkey showed that Turkish $\mathrm{BL}$ appears in a form that is between the endemic and the sporadic form. A recent study conducted by Ogwang et al. reported that there are some changes in the endemic form in Uganda over time [9]. Our findings showed that the abdominal presentation tends to increase, and there is a shift like Ogwang et al.s work at our center in Turkey. We consider that new studies are needed to detect change all over the world.

Peer-review: Externally peer-reviewed.

Conflict of Interest: No conflict of interest was declared by the authors.

Ethics Committee Approval: Ethics committee consent was obtained from the Dr. SUCH ethics committee.

Financial Support: The authors declared that this study has received no financial support.

Authorship contributions: Concept - E.B.; Design - C.B.; Supervision - N.Y.; Funding - None; Materials - E.B.; Data collection and/or processing - E.B.; Data analysis and/or interpretation - E.B.; Literature search - S.İ.Ö.; Writing - E.B.; Critical review - G.Ş.

\section{References}

1. Miles RR, Arnold S, Cairo MS. Risk factors and treatment of childhood and adolescent Burkitt lymphoma/ leukaemia. Br J Haematol 2012;156(6):730-43.

2. Ferry JA. Burkitt's Lymphoma: Clinicopathologic Features and Differential Diagnosis. Oncologist 2006;11(4):375-83.

3. Leoncini L, Raphael M, Stein H, Harris NL, Jaffe ES, Kluin PM. Burkitt Lymphoma. In; Swerdlow SH, Campo E, Harris NL, Jaffe ES, Pileri SA, Stein H, Thiele J, Vardiman JW, editors. WHO Classification of Tumours of Haematopoietic and Lymphoid Tissues, $4^{\text {th }}$ edition. Lyon, France: IARC Press, 2008.p. 262-4.

4. Hudson MM, Onciu M, and Donaldson SS. Hodgkin lymphoma. In: Pizzo PA, Poplack DG editors. Principles, and Practice of Pediatric Oncology, 7th ed. Philedelphia: Lipincott Williams \& Wilkins, 2011. p. 722-36.

5. Lanzkowsky P. Manuel of Pediatric Hematology and Oncology, 4th edition. Elsevier, 2005.p. 491-511,777,786.

6. Robertson ES. Burkitt lymphoma. New York: Springer; 2013. p. 81-131.

7. Wright $\mathrm{DH}$, Addis BJ, Leong ASY. Diagnostic Lymph Node Pathology, 2nd edition. CRC Press, 2011. p. 85-6.

8. Cairo MS, Sposto R, Perkins SL, Meadows AT, HooverRegan ML, Anderson JR, et al. Burkitt's and Burkitt- 
like lymphoma in children and adolescents: a review of the Children's Cancer Group experience. Br J Haematol 2003;120(4):660-70.

9. Ogwang MD, Bhatia K, Biggar RJ, Mbulaiteye SM. Incidence and geographic distribution of endemic Burkitt lymphoma in northern Uganda revisited. Int J Cancer 2008;123(11):2658-63.

10.Al-Attar A, Pritchard J, Al-Saleem T, Al-Naimi M, Alash N, Attra A. Intensive chemotherapy for non-localised Burkitt's lymphoma. Arch Dis Child 1986;61(10):1013-9.

11. Murphy SB, Bowman WP, Abromowitch M, Mirro J, Ochs J, Rivera G, et al. Results of treatment of advanced-stage Burkitt's lymphoma and B cell (SIg+) acute lymphoblastic leukemia with high-dose fractionated cyclophosphamide and coordinated high-dose methotrexate and cytarabine. J Clin Oncol 1986;4(12):1732-9.

12. Cunha KC, Oliveira MC, Gomes AC, de Castro LP, Viana MB. Clinical course and prognostic factors of children with Burkitt's lymphoma in a developing country: the experience of a single centre in Brazil. Rev Bras Hematol Hemoter 2012;34(5):361-6.

13. Ertem U, Duru F, Pamir A, Taçyildiz N, Dağdemir A, Akçayöz A, et al. Burkitt's Lymphoma in 63 Turkish Children Diagnosed Over a 10 Year Period. Pediatric Hematology and Oncology 1996;13(2):123-34.

14. Tinaztepe B, Gögüus S, Tinaztepe S. Burkitt lenfoma: Hacettepe Çocuk Hastanesinde görülen 32 vakanın patolojik incelenmesi ve Afrikalı çocuklardakilerle karşılaştırılması. Turkish J Pathology 1975;2(3):201-11.

15. Cavdar AO, Gözdaşoğlu S, Yavuz G, Babacan E, Unal $\mathrm{E}$, Uluoğlu $\mathrm{O}$, et al. Burkitt's lymphoma between African and American types in Turkish children: clinical, viral (EBV), and molecular studies. Med Pediatr Oncol 1993;21(1):36-42.

16. Cavdar AO, Yavuz G, Babacan E, Gözdasoglu S, Unal E, Ertem U, et al. Burkitt's lyphoma in Turkish children: clinical, viral (EBV) and molecular studies. Leukemia \& Lymphoma 1994;14(3-4):323-30.

17. Karakaş Z, Bülbül A, Anak S, Ünüvar A, Sarıbeyoglu ET, Devecioglu Ö, et al. Burkitt's lymphoma in childhood : ten years follow-up. Türk Onkoloji Derg 2004;19(1):3-8.

18. Celkan TT, Bariş S, Ozdemir N, Ozkan A, Apak $\mathrm{H}$, Doğru O, et al. Treatment of pediatric Burkitt lymphoma in Turkey. J Pediatr Hematol Oncol 2010;32(7):e279-84.

19. Karadeniz C, Oguz A, Citak EC, Uluoglu O, Okur V, Demirci $S$, et al. Clinical characteristics and treatment results of pediatric B-cell non-Hodgkin lymphoma patients in a single center. Pediatr Hematol Oncol 2007;24(6):417-30.
20. Kutluk T, Varan A, Akyüz C, Büyükpamukçu M. Clinical characteristics and treatment results of LMB/LMT regimen in children with non-Hodgkin's lymphoma. Cancer Invest 2002;20(5-6):626-33.

21. Burkhardt B, Zimmermann M, Oschlies I, Niggli F, Mann G, Parwaresch R, Riehm H, et al. The impact of age and gender on biology, clinical features and treatment outcome of non-Hodgkin lymphoma in childhood and adolescence. Br J Haematol 2005;131(1):39-49.

22. Mbulaiteye SM, Biggar RJ, Bhatia K, Linet MS, Devesa SS. Sporadic childhood Burkitt lymphoma incidence in the United States during 1992-2005. Pediatr Blood Cancer 2009;53(3):366-70.

23. Mwanda OW, Rochford R, Moormann AM, Macneil A, Whalen C, Wilson ML. Burkitt's lymphoma in Kenya: geographical, age, gender and ethnic distribution. East Afr Med J 2004;81(8):68-77.

24. Orem J, Mbidde EK, Lambert B, de Sanjose S, Weiderpass E. Burkitt's lymphoma in Africa, a review of the epidemiology and etiology. Afr Health Sci 2007;7(3):166-75.

25. Owusu L, Yeboah FA, Osei-Akoto A, Rettig T, Arthur FK. Clinical and epidemiological characterisation of Burkitt's lymphoma: an eight-year case study at Komfo Anokye Teaching Hospital, Ghana. Br J Biomed Sci 2010;67(1):9-14.

26. Patte C, Auperin A, Michon J, Behrendt H, Leverger G, Frappaz D, et al. The Société Française d'Oncologie Pédiatrique LMB89 protocol: highly effective multiagent chemotherapy tailored to the tumor burden and initial response in 561 unselected children with B-cell lymphomas and L3 leukemia. Blood 2001;97(11):3370-9.

27. Hassan R, Klumb CE, Felisbino FE, Guiretti DM, White LR, Stefanoff CG, et al. Clinical and demographic characteristics of Epstein-Barr virus-associated childhood Burkitt's lymphoma in Southeastern Brazil: epidemiological insights from an intermediate risk region. Haematologica 2008;93(5):780-3.

28. Cairo MS, Sposto R, Gerrard M, Auperin A, Goldman SC, Harrison L, et al. Advanced stage, increased lactate dehydrogenase, and primary site, but not adolescent age ( $\geq 15$ years), are associated with an increased risk of treatment failure in children and adolescents with mature B-cell non-Hodgkin's lymphoma: results of the FAB LMB 96 study. J Clin Oncol 2012;30(4):387-93.

29. Al-Attar A, Attra A, Al-Bagdadi R, Al-Naimi M, AlSaleem T, Pritchard J. Debulking' surgery is unnecessary in advanced abdominal Burkitt lymphoma in Iraq. Br J Cancer 1989;59:610-2.

30. Link MP, Shuster JJ, Donaldson SS, Berard CW, Murphy SB. Treatment of children and young adults with early-stage non-hodgkin's lymphoma. New England J Med 1997;337:1259-66. 